\title{
Coronary Angiography with Gadolinium in Patients with Severe Allergy to lodinated Contrast Media
}

\author{
George César Ximenes Meireles , Sérgio Kreimer², Gilberto Guilherme Ajjar Marchiori, \\ Micheli Zanotti Galon ${ }^{4}$, Rafael Scanavacca ${ }^{5}$
}

\begin{abstract}
lodinated contrast media use is contraindicated in some patients due to serious life-threatening adverse events. In such cases, there have been reports that gadolinium (gadobutrol), which is commonly employed in magnetic resonance imaging, can be used as a contrast media for coronary angiography. This study reports two patients with histories of severe allergies to iodinated contrast agents who underwent coronary angiography with gadolinium. The procedures were well tolerated. The amount of contrast media did not exceed 0.3 to $0.4 \mathrm{~mL} / \mathrm{kg}$, and the images obtained were of acceptable quality for diagnostic purposes.
\end{abstract}

DESCRIPTORS: Coronary artery disease, Coronary angiography, Contrast media, Gadolinium.

odinated contrast agents are commonly used to perform coronary angiography and coronary angioplasty, and are generally well tolerated. However, complications can occur; contrast nephropathy and allergic reactions are the most frequently reported. Most allergic reactions can be prevented by the prior use of corticosteroids and antihistamines. A gadolinium-based contrast may be an option when there are contraindications for using iodinated contrasts due to severe allergic reactions. ${ }^{1}$

Most contrast agents used in magnetic resonance imaging (MRI) examinations are based on paramagnetic gadolinium ion chelates, which have been used since the late 1980s. In general, gadolinium-based contrast agents are considered to be much safer than iodinated
RESUMO

\section{Cinecoronariografia com Gadolínio em Pacientes com Alergia Grave ao Contraste Iodado}

Em alguns pacientes a utilização dos meios de contraste iodados é contraindicada pela possibilidade de desencadearem efeitos colaterais graves ameaçadores da vida. Nesses casos, existem relatos em que o gadolínio (gadobutrol), comumente empregado na ressonância nuclear magnética, pode ser usado como meio de contraste para coronariografia. Relatamos dois casos com antecedente de alergia grave ao contraste iodado, que realizaram coronariografia com gadolínio. Os procedimentos foram bem tolerados, a quantidade de contraste não excedeu $0,30,4 \mathrm{ml} / \mathrm{kg}$ e as imagens obtidas foram de qualidade aceitável para efeitos de diagnóstico.

DESCRITORES: Doença da artéria coronariana. Angiografia coronária. Meios de contraste. Gadolínio.

agents. The gadolinium ion is quite toxic when circulating freely, and it has a biological half-life of a few weeks, which is much higher than the approximately 1.5-hour half-life of gadolinium chelate compounds. The gadolinium ion, when chelated to a molecule, has its pharmacokinetics altered, which accelerates its clearance and sharply decreases its toxicity. Gadolinium chelation allows for an increase of up to 500 times the rate of the renal excretion of the compound. The chelating agent is what differentiates the various gadolinium-based contrast media available in the market. $^{2}$

The use of intra-arterial gadolinium-based contrast media is considered 'off-label', as it is indicated only for intravenous administration. Intra-arterial gadolinium use was first described by Pavone et al. ${ }^{3}$ in a study

\footnotetext{
${ }^{1}$ Ph.D., Director of the Department of Haemodynamics and Interventional Cardiology, Hospital do Servidor Público Estadual. São Paulo, SP, Brazil.

2 Physician, Interventional cardiologist in the Department of Haemodynamics and Interventional Cardiology, Hospital do Servidor Público Estadual. São Paulo, SP, Brazil.

3 Physician, Interventional cardiologist in the Department of Haemodynamics and Interventional Cardiology, Hospital do Servidor Público Estadual. São Paulo, SP, Brasil.
}

\footnotetext{
${ }^{4}$ Master's Degree. Physician, Interventional cardiologist in the Depart ment of Haemodynamics and Interventional Cardiology, Hospital do Servidor Público Estadual. São Paulo, SP, Brazil.

${ }^{5}$ Cardiology resident in the Department of Cardiology, Hospital do Servidor Público Estadual. São Paulo, SP, Brazil.

Correspondence to: George César Ximenes Meireles. Rua Sena Madureira, 1.265 - Vila Mariana - São Paulo, SP, Brasil - CEP 04021051 Email: george.ximenes@terra.com.br

Received: 5/14/2012 • Accepted: 8/30/2012
} 
of arterial portography in 12 patients with hepatic lesions. Since then, it has been used for peripheral and cerebral arteriography, coronary angiography, and coronary angioplasty in patients with severe reactions to iodinated contrast. ${ }^{1,2,4,5}$

The prevalence of allergic reactions to gadolinium is uncommon $(0.07 \%)$, and higher in patients with histories of allergic reactions to iodinated contrast agents. ${ }^{1,6}$ The incidence of anaphylaxis ranges from 1/100,000 to 1/500,000 administrations of gadolinium.

This study reports two cases of iodinated contrast agent substitution with gadolinium to perform coronary angiography in patients with contraindications to iodinated contrast media due to severe allergic reactions.

\section{CASE REPORTS}

\section{Case 1}

Case 1 was a 63-year-old female patient with a history of dyspnea and chest pain (beginning three months prior) radiating to the left arm. The pain was related to ordinary activities, lasted three minutes, and improved with rest. The patient had experienced a previous myocardial infarction and had a history of angioedema and urticaria related to an examination with iodinated contrast. The patient's blood pressure was 130/80 $\mathrm{mmHg}$, and her heart rate was $62 \mathrm{bpm}$. Cardiopulmonary auscultation was normal.

The electrocardiogram at rest evidenced sinus rhythm and slow $\mathrm{R}$ wave progression at $\mathrm{V} 1-\mathrm{V} 4$. A transthoracic echocardiogram showed concentric left ventricular hypertrophy and moderate left ventricular anteroapical wall hypocontractility. Dipyridamole myocardial scintigraphy presented pronounced transient hypo-uptake in the left ventricular anterior wall. A coronary angiography was then indicated.

Skin tests were performed with iodinated contrast media: the skin prick test with multiple dilutions, whose results were negative, and the intradermal test with pure substances, which showed positive results, contraindicating the procedure with iodinated contrast. The skin test was negative for gadolinium.

Three days prior to the coronary angiography, the patient was treated with $180 \mathrm{mg} /$ day of fexofenadine orally and $20 \mathrm{mg}$ of prednisone orally every eight hours, beginning the day before the examination.

A coronary angiography was performed via femoral artery access (5 F introducer and catheter); it revealed left circumflex and right coronary arteries lesions with no significant injury and $100 \%$ lesion of the middle third of the left anterior descending artery. Collateral circulation was present in the right coronary artery to the left anterior descending artery $(+++/ 4+)$, and a left ventriculography was not performed. $34 \mathrm{~mL}$ of gadobutrol
(Gadovist ${ }^{\circledR}$, Bayer Schering Pharma - Berlin, Germany) were used, and the procedure was uneventful.

A coronary artery bypass graft (CABG) surgery was performed one week after the coronary angiography (anastomosis of the left internal thoracic artery left anterior descending artery (LAD). The patient had an uneventful recovery and was discharged on the tenth postoperative day.

\section{Case 2}

Case 2 was a 55-year-old female patient with a history of chest pain that radiated to the left arm at mild exertion, lasted 15 to 20 minutes, and improved with rest. She reported fibromyalgia and a history of allergy to iodinated contrast (anaphylactic shock), sulpha drugs, dipyrone, and non-steroidal anti-inflammatory drugs. The patient's blood pressure was $120 / 80 \mathrm{mmHg}$, and her heart rate was $75 \mathrm{bpm}$. The cardiopulmonary auscultation was normal.

At rest, the electrocardiogram showed sinus rhythm with isolated ventricular extrasystoles and left ventricular overload. The transthoracic echocardiogram showed left ventricular ejection fraction of $43 \%$, systolic segment dysfunction (septal akinesia), and left ventricular relaxation alteration. A coronary angiography was then indicated.

Because of the history of anaphylaxis to iodinated contrast, no allergy tests for iodinated contrast agents were performed. The patient was treated prior to the coronary angiography with $180 \mathrm{mg} /$ day of fexofenadine orally, $25 \mathrm{mg}$ of hydroxyzine, and $20 \mathrm{mg}$ of prednisone orally every eight hours, beginning 25 hours before the procedure.

A coronary angiography was performed via femoral artery access (5 F introducer and catheter); it showed coronary arteries with parietal irregularities. Left ventriculography was not performed. A total of $30 \mathrm{~mL}$ of gadobutrol was used, and the procedure was uneventful. The patient was discharged the next day.

\section{DISCUSSION}

This is the first publication in the English language regarding the use of gadobutrol in place of iodinated contrast for coronary angiography in patients with histories of severe allergies to iodine. Considering that severe life-threatening allergic reactions after using iodinated contrast are rare (1 death per 55,000 cases) ${ }^{7}$ and that most patients respond satisfactorily to previous preparation with corticosteroid and antihistamine, it is difficult to find studies using gadolinium as a substitute for iodinated contrast in patients undergoing coronary angiography; publications are limited to case reports.

Since the clinical use of high doses of intra-arterial gadolinium has not been studied, it is prudent to restrict its use to 0.3 to $0.4 \mathrm{mmol} / \mathrm{kg}$ (equivalent to 0.3 to $0.4 \mathrm{~mL} / \mathrm{kg}$ ). ${ }^{2}$ 
Thus, tests performed with gadolinium should be carefully planned and use few views (adequately defining the coronary arteries), limit the number and volume of test injections, and forego the ventriculography.

The acute adverse reactions to intravenous gadolinium use can be divided into major, severe, and minor; and between general and local. The overall incidence of adverse reactions to MRI contrast agents varies between approximately $2 \%$ and $4 \%$. The most common general minor reactions are nausea, vomiting, rash, and headache, while common local reactions are irritation, burning sensations, and a feeling of cold. Cases of acute adverse reactions to gadolinium, such as laryngospasm and anaphylaxis, are rare. ${ }^{8}$ Adverse reactions after intravenous injection of gadolinium are more frequent in patients who have had previous reactions to any internal contrast use, either gadolinium or iodine contrast (twice the chance), and in patients with histories of asthma and allergies. ${ }^{9}$

The effects of intra-arterial gadolinium use have been little studied, and most case reports in the literature do not mention any adverse reactions to gadolinium. ${ }^{1,3-5}$

The intracoronary injection of gadolinium can result in severe cardiac arrhythmia (ventricular fibrillation), which is caused by the osmolality (700 mOsm/kg) of the contrast injected directly into the coronary artery, more than twice the plasmatic osmolality. ${ }^{10}$ Another effect is nephrotoxicity, which may occur with high doses of gadolinium, although it is less nephrotoxic than the iodinated contrasts. ${ }^{1}$ Gadolinium should not be used in patients with chronic renal failure (estimated creatinine clearance $<30 \mathrm{~mL} / \mathrm{min} / \mathrm{L}, 1.73 \mathrm{~m}^{2}$ ) or in patients with acute renal failure of any severity due to the risk of developing nephrogenic systemic fibrosis. ${ }^{11}$

The seriated control of creatinine (post-procedure) in the present cases showed no alterations, which indicated that the doses used were safe.

The femoral technique was chosen due to the volume of gadolinium contrast, as the catheterisation of the coronary arteries using the femoral technique is usually easier to perform when compared to the radial access technique, and there is a decreased need for contrast tests to determine the location.

The major limitations to using gadolinium in angiography are the opacity, which is less than that of the iodinated contrast, and the maximum volume that can be used. In these cases, the images were of acceptable quality, clearly defining the coronary anatomy and the presence or absence of obstructive lesions (Figures 1 and 2).

Thus, it can be concluded that the gadolinium contrast medium is a potential alternative for patients with severe allergy to iodinated contrast media who require coronary angiography.

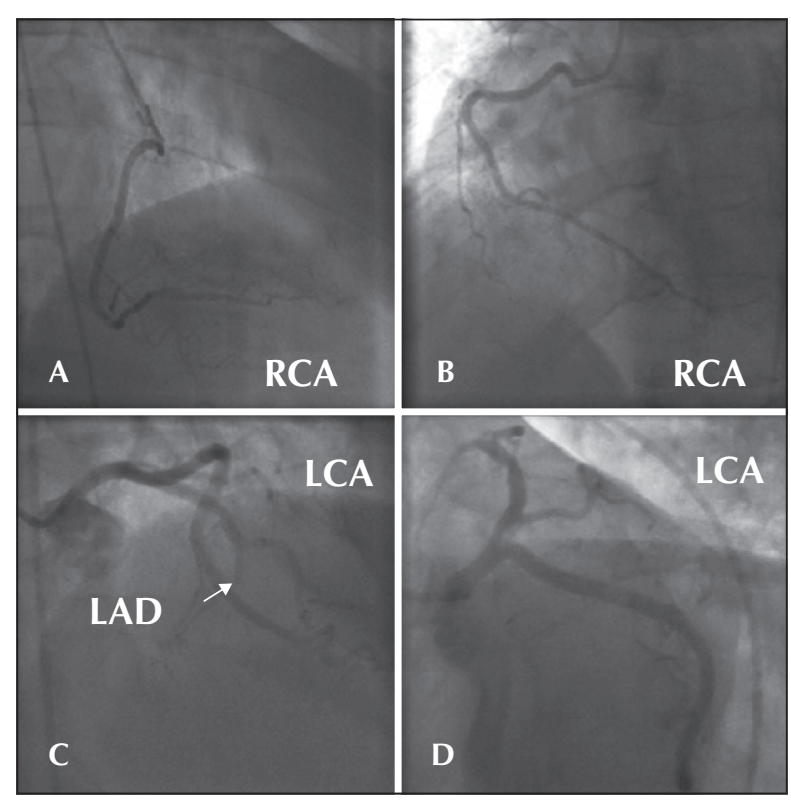

Figure 1 - Case 1. A) Right coronary artery in the right anterior oblique view. B) Right coronary artery in the left anterior oblique view. C) Left coronary artery in the right anterior oblique cranial view and the left anterior descending artery with total obstruction in the middle third (arrow). D) Left coronary artery in the left anterior caudal oblique view. $\mathrm{RCA}=$ right coronary artery, LCA = left coronary artery, LAD = left anterior descending artery.
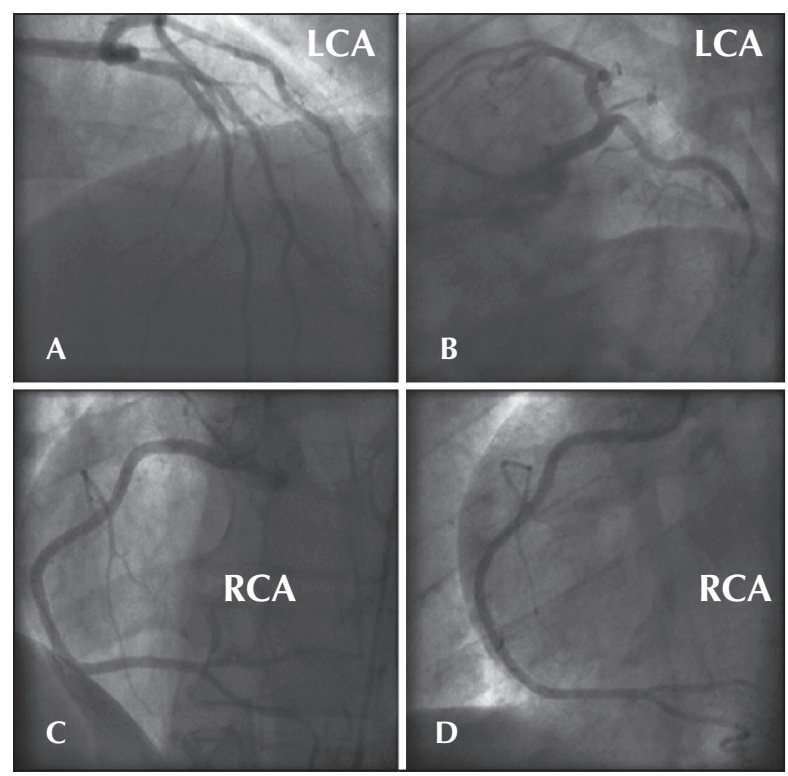

Figure $\mathbf{2}$ - Case 2. A) Left coronary artery in the right anterior oblique cranial view. B) Left coronary artery in the left anterior oblique caudal view. C) Right coronary artery in the cranial posteroanterior view. D) Right coronary artery in the left anterior oblique view. RCA = right coronary artery, LCA = left coronary artery. 


\section{CONFLICTS OF INTEREST}

The authors declare no conflicts of interest.

\section{REFERENCES}

1. Ose K, Doue T, Zen K, Hadase M, Sawada T, Azuma A, et al. Gadolinium as an alternative to iodinated contrast media for X-ray angiography in patients with severe allergy. Circ J. 2005;69(4):5079.

2. Spinosa DJ, Kaufmann JA, Hartwell GD. Gadolinium chelates in angiography and interventional radiology: a useful alternative to lodinated contrast media for angiography. Radiology. 2002; 223(2):31925.

3. Pavone P, Giuliani S, Cardone G, Occhiato R, Di Renzi P, Petroni GA, et al. Intraarterial portography with gadopentetate dimeglumine: improved livertolesion contrast in MR imaging. Radiology. 1991;179(3):6937.

4. Arat A, Cekirge HS, Saatci I. Gadodiamide as an alternative contrast medium in cerebral angiography in a patient with sensitivity to iodinated contrast medium. Neuroradiology. 2000; 42(1):347.

5. Furuichi S, Yasuda S, Arita Y, Miyawaki M, Nomura K, Nonogi H, et al. Gadopentetate dimeglumine as a potential alternative contrast medium during percutaneous coronary intervention. Circ J. 2004;68(10):9723.
6. Dillman JR, Ellis JH, Cohan RH, Strouse PJ, Jan SC. Frequency and severity of acute allergiclike reactions to gadolinium-containing i.v. contrast media in children and adults. AJR Am J Roentgenol. 2007;189(6):15338.

7. Goss JE, Chambers CE, Heupler FA Jr. Systemic anaphylactoid reactions to iodinated contrast media during cardiac catheterization procedures: guidelines for prevention, diagnosis, and treatment. Laboratory Performance Standards Committee of the Society for Cardiac Angiography and Interventions. Cathet Cardiovasc Diagn. 1995;34(2):99104.

8. Li A, Wong CS, Wong MK, Lee CM, Au Yeung MC. Acute adverse reactions to magnetic resonance contrast mediagadolinium chelates. Br J Radiol. 2006;79(941):36871.

9. Greenberger PA, Patterson R, Tapio CM. Prophylaxis against repeated radiocontrast media reactions in 857 cases: adverse experience with cimetidine and safety of betaadrenergic antagonists. Arch Intern Med. 1985;145(12):2197200.

10. Kälsch H, Kälsch T, Eggebrecht H, Konorza T, Kahlert P, Erbel R. Gadolinium-based coronary angiography in patients with contraindication for iodinated X-ray contrast medium: a word of caution. J Interv Cardiol. 2008;21(2):16774.

11. Thomsen HS. How to avoid nephrogenic systemic fibrosis: current guidelines in Europe and the United States. Radiol Clin North Am. 2009;47(5):8715. 